\title{
Extensive genetic recombination occurs in the field between different genotypes of Ehrlichia ruminantium
}

\author{
M.T.E.P. Allsopp ${ }^{\mathrm{a}, 1}$ and B.A. Allsopp ${ }^{\mathrm{b}}$ \\ ${ }^{a}$ Onderstepoort Veterinary Institute, Private Bag X5, Onderstepoort 0110, South Africa \\ ${ }^{b}$ Department of Veterinary Tropical Diseases, Faculty of Veterinary Science, University \\ of Pretoria, Private Bag X04, Onderstepoort 0110, South Africa
}

\begin{abstract}
The intracellular bacterium Ehrlichia ruminantium is the causative agent of heartwater throughout sub-Saharan Africa, Madagascar, and some islands of the Caribbean. The disease is tick-borne and causes substantial livestock losses, threatening food security and productivity in both the commercial and small-scale farming sectors in endemic areas. Immunization by infection and treatment is currently practised in South Africa, and it is known that a variety of immunotypes of the organism occur in the field, and that crossprotection between them varies widely from total to minimal. Future vaccines may therefore need to incorporate components from different genotypes so it is essential to have information on the extent of genetic variation among isolates. To obtain this information we amplified and sequenced a panel of eight core function genes from 12 different cultured stocks originally isolated in different areas of Africa and the Caribbean. Phylogenetic trees inferred from the sequences yielded different branching orders for different genes, and the reason for this inconsistency appears to be that extensive recombination takes place between different genotypes in the field. It is possible that recombination occurs during the period when the organisms are extracellular within the tick, immediately after feeding and before intracellular infection is established, although detection of more than one genotype in DNA from single ticks is encountered infrequently. The results of the analysis show that the phylogenetic variation is greatest
\end{abstract}


among the isolates of southern African origin, suggesting that this is the region where the parasite first evolved. It also appears likely that the Gardel genotype, isolated in the Caribbean, originally came from west central Africa, not from west Africa as had long been assumed.

\section{Article Outline}

1. Introduction

2. Materials and methods

3. Results

4. Discussion

5. Conclusion

Acknowledgements

References

\section{Introduction}

The intracellular bacterium, Ehrlichia ruminantium, is the causative agent of heartwater throughout sub-Saharan Africa, Madagascar, and some islands of the Caribbean. The disease is transmitted by ticks of the genus Amblyomma and it causes substantial livestock losses, threatening food security and productivity in both the commercial and small-scale farming sectors (Provost and Bezuidenhout, 1987). There is no satisfactory vaccine which provides widespread protection against field challenge, but an infection and treatment immunization regime is currently practised in southern Africa. This utilises sheep blood infected with live organisms of a strain of E. ruminantium (Ball3) which causes a slow onset of disease symptoms, allowing timely treatment with tetracyclines to be administered (Van der Merwe, 1987). Production and administration of this vaccine is costly and demanding, and it confers only limited protection against some common genotypes (Du Plessis et al., 1989). It has long been recognized that a variety of immunotypes of E. ruminantium occur in the field, and that cross-protection between them varies widely from total to minimal (Jongejan et al., 1991). There are also genotypes in circulation which are phylogenetically classified as E. ruminantium but 
which apparently cause no disease (Allsopp et al., 2006). For these reasons future vaccines will almost certainly have to incorporate components from several isolates, so it is essential to gather information on the extent of genetic variation among isolates. The initial objective of this work was, therefore, to develop a genetic database representative of the genotypic variability in existence in the field for the characterization of present and future isolates of E. ruminantium. An early attempt to obtain such information had concentrated on the outer membrane protein map 1 gene, but this was found to be highly variable and it did not show any correlation with virulence, immunogenicity or geographical origin (Allsopp et al., 2001). We decided therefore to examine core function genes, which are shared between members of a species by horizontal gene transfer, and have been proposed in the Core Genome Hypothesis as a means of defining bacterial species (Lan and Reeves, 2001). We selected eight genes, some of which had already been used for the characterisation of E. ruminantium (Allsopp et al., 1999) and other Rickettsiales ([Ishikura et al., 2003] and [Lee et al., 2003]). We obtained the sequences of these genes from 12 different cultured stocks of E. ruminantium isolated in different areas of Africa and the Caribbean, and subjected the data to phylogenetic analysis.

\section{Materials and methods}

Twelve E. ruminantium stocks were chosen for inclusion in the study according to their availability in culture at Onderstepoort and their range of geographical origins, the details of which are shown in Table 1. Aliquots $(2 \mathrm{ml})$ of E. ruminantium culture supernatants were spun at $16,000 \times g$ for $20 \mathrm{~min}$ at $4{ }^{\circ} \mathrm{C}$ to pellet elementary bodies. The supernatants were discarded and the pellets were resuspended in $200 \mu 1$ sterile phosphate buffered saline (PBS) to remove any culture medium. After re-centrifugation under the same conditions, pellets were resuspended in $200 \mu \mathrm{PBS}$. DNA was extracted into a final volume of $100 \mu \mathrm{l}$ of elution buffer, using the GENTRA 'Generation Capture Column' system (Gentra Corp. Minnesota, USA). Eight core function genes were selected for amplification; 16S rRNA, gltA, groEL, ftsZ, sodB, nuoB, rnc and ctaG. The two latter genes overlap in the genomic region designated pCS20 (Waghela et al., 1991). Table 2 lists the genes, together with the sequences of the primers used to amplify them, and the Erum identification numbers of their orthologs in the E. ruminantium (Welgevonden) 
complete genome sequence (Collins et al., 2005). The genes were amplified from $E$. ruminantium DNA as described elsewhere (Van Heerden et al., 2004), except that the annealing temperatures were optimised for each gene (Table 2). When single welldefined amplicons were obtained they were directly sequenced using appropriately diluted amplification primers. Where multiple bands were obtained, both the band corresponding to the correct sized amplicon, as well as several of the bands of unexpected size, were gel-purified using the Qiagen MinElute system (Qiagen, Hilden, Germany). Gel purified amplicons were cloned into pGEM-T vector (Promega, Madison, USA) and recombinant plasmids were purified using the High Pure Plasmid Isolation kit (Roche Diagnostics, Mannheim, Germany). To obtain a consensus sequence for the cloned amplicons, and to reduce the possibility of polymorphisms due to PCR misincorporation errors, at least four recombinants were sequenced for each gene. All sequencing was done using BigDye chemistry (Applied Biosystems) on an ABI3100 sequencer and all kits were used as recommended by the manufacturers. For each gene the lengths of reliable sequence available from all the stocks (shown in Table 4) were aligned using CLUSTALW (Thompson et al., 1994) and subjected to maximum likelihood phylogenetic analysis using PHYML (Guindon and Gascuel, 2003). A concatenated alignment of the eight genes was also constructed and analysed separately, and the corresponding E. canis ortholog sequences were obtained from GenBank and included in the alignment to root the tree. Sequences determined as part of this study, if not already in the public domain, were submitted to GenBank with the following accession numbers:

\begin{tabular}{|l|l|}
\hline $16 \mathrm{~S}$ & DQ647615-DQ647616 \\
\hline pCS20 & DQ655712-DQ655713 \\
\hline gltA & DQ513389-DQ513397 \\
\hline groEL & DQ647003-DQ647014 \\
\hline ftsZ & DQ646992-DQ647002 \\
\hline sodB & DQ647015-DQ647026 \\
\hline nuoB & DQ833442-DQ833453 \\
\hline
\end{tabular}


Table 1.

E. ruminantium stocks used in this study

\begin{tabular}{|l|l|l|}
\hline Stock & Origin & Reference \\
\hline Welgevonden & Transvaal, South Africa & Du Plessis (1985) \\
\hline Mara87/7 & Transvaal, South Africa & Du Plessis et al. (1989) \\
\hline Ball3 & Transvaal, South Africa & Haig (1952) \\
\hline Blaauwkrans & Eastern Cape, South Africa & (Du Plessis, personal communication) \\
\hline Umbanein & Sudan & Jongejan et al. (1984) \\
\hline Kiswani & Kenya & Kocan et al. (1987) \\
\hline Kümm2 & Transvaal, South Africa & $\begin{array}{l}\text { Du Plessis and Kumm (1971); Zweygarth et } \\
\text { al. (2002) }\end{array}$ \\
\hline Kümm1 & Transvaal, South Africa & \\
\hline Senegal & Senegal & Jongejan et al. (1988) \\
\hline Sankat & Ghana & Bell-Sakyi et al. (1997) \\
\hline Pokoase & Ghana & Guadeloupe, French West \\
\hline Gardel & Indies & Uilenberg et al. (1984) \\
\hline
\end{tabular}


Table 2.

E. ruminantium core-function genes and the primers used for their amplification

\begin{tabular}{|c|c|c|c|c|c|c|}
\hline $\begin{array}{l}\text { Target } \\
\text { gene }\end{array}$ & $\begin{array}{l}\text { Erum } \\
\text { number }^{a}\end{array}$ & $\begin{array}{l}\text { Lengt } \\
\text { h (bp) }\end{array}$ & Forward primer $\left(5^{\prime}-3^{\prime}\right)$ & Reverse primer $\left(5^{\prime}-3^{\prime}\right)$ & $\begin{array}{l}\boldsymbol{T}_{\mathbf{m}} \\
{ }_{\mathrm{b}}^{\circ} \mathbf{C}\end{array}$ & $\begin{array}{l}\text { Primer } \\
\text { referenc } \\
\text { e }\end{array}$ \\
\hline $16 S$ & N/A & 1458 & CAGAGTTTGATCCTGGCTCAG & AAGGAGGTGATCCAGCC & 65 & $\begin{array}{l}\text { Weisburg } \\
\text { et al. } \\
(1991)\end{array}$ \\
\hline rnc & 8070 & 684 & see pCS20 & see pCS20 & & \\
\hline$c t a G$ & 8080 & 534 & see pCS20 & see pCS20 & & \\
\hline$\underset{\mathrm{c}}{\mathrm{pCS} 20}$ & $8070 ; 8080$ & 1218 & $\begin{array}{l}\text { CCCTATGATACAGAAGGTAACCTC } \\
\text { GC }\end{array}$ & $\begin{array}{l}\text { GATAAGGAGATAACGTTTGTTTG } \\
\text { G }\end{array}$ & 62 & $\begin{array}{l}\text { Van } \\
\text { Heerden } \\
\text { et al. } \\
\text { (2004) }\end{array}$ \\
\hline gltA & 0750 & 1248 & ATTGTATTAGGTAGAATTATG & GGAAATACCTTCACTACTAC & 57 & $\begin{array}{l}\text { Collins et } \\
\text { al. } \\
(2005) \text {. }\end{array}$ \\
\hline groEL & 6420 & 1656 & GTGGGCTGGTAATGAAGTG & CACCTGGCACAACACCTTC & 60 & \\
\hline ftsZ & 8800 & 1269 & CTTTATTACGTATTCAATAGT & AAAGCCAATAAGACATTGG & 55 & \\
\hline пиов & 3090 & 519 & AATGGGAGTAATTTTATATG & TAAGTACTTTTTTTAAGTGG & 55 & \\
\hline sodB & 5270 & 633 & AATTTGGAGGGATATATG & GCATCTTAGGAAAATATTTA & 55 & \\
\hline
\end{tabular}


${ }^{a}$ Erum numbers identify orthologs in the E. ruminantium (Welgevonden) genome sequence (Collins et al., 2005).

${ }^{\mathrm{b}} T_{\mathrm{m}}$ refers to the annealing temperature used in the PCR amplifications, not the calculated annealing temperatures of the individual primers.

${ }^{\mathrm{c}}$ pCS20 designates a genomic region used for diagnostic purposes which includes two overlapping genes.

\section{Results}

Sequences were obtained for all 8 genes for 11 stocks, but for the Kümm2 stock only 7 genes were amplified, no amplicon could be obtained for gltA. All sequences from bands of unexpected size were found to match mammalian chromosomal sequences in GenBank. Differences between orthologous E. ruminantium sequences consisted of single nucleotide polymorphisms (SNPs) spread throughout the sequenced regions. The majority of the SNPs in the protein coding genes were neutral mutations, and in the case of the $16 \mathrm{~S}$ gene the majority occurred in the hypervariable V1 loop.

The sequences for the different stocks were analysed in the order in which they are given in Table 3, starting with the Welgevonden stock, whose sequences were assigned the 'Welg' code. The next to be analysed, the Mara87/7 sequences, were all different from their Welgevonden orthologs and were assigned the 'M87' code. Subsequently the Ball3 sequences were examined, most of these were also new and were assigned a 'B3' code. The exceptions were the pCS20 and sodB sequences, which were identical to their Welgevonden orthologs, and the nuoB sequence, which was identical to that of Mara87/7, and these three sequences were given appropriate codes. The analysis was completed in this fashion to yield the mosaic pattern seen in Table 3. 
Table 3.

Identities of the sequences of eight core function genes from 12 different E. ruminantium stocks

\begin{tabular}{|l|l|l|l|l|l|l|l|l|}
\hline Stock & Code & Sequence identity of gene or genetic region \\
\hline & & $\mathbf{1 6 S}$ & rnc and ctaG & gltA & groEL & ftsZ & sodB & nuoB \\
\hline Welgevonden & Welg & Welg & Welg & Welg & Welg & Welg & Welg & Welg \\
\hline Mara87/7 & M87 & M87 & M87 & M87 & M87 & M87 & M87 & M87 \\
\hline Ball3 & B3 & B3 & Welg & B3 & B3 & B3 & Welg & M87 \\
\hline Blaauwkrans & Blk & Welg & Blk & Blk & Welg & Blk & Blk & Blk \\
\hline Umbanein & Umb & M87 & Umb & Umb & B3 & Welg & Welg & Welg \\
\hline Kiswani & Kis & Kis & Kis & Kis & Kis & Kis & Kis & Welg \\
\hline Kümm2 & Km2 & Km2 & Km2 & NA & Km2 & Km2 & M87 & Km2 \\
\hline Kümm1 & Km1 & Km1 & Km1 & Km1 & Km1 & Km1 & Km1 & Km1 \\
\hline Senegal & Sen & Km1 & Km1 & Sen & Km1 & Sen & Sen & Sen \\
\hline Sankat & Sank & Km1 & Km1 & Sank & Km1 & Sank & Sank & Sank \\
\hline Pokoase & Pok & Km1 & Km1 & Km1 & Pok & Sen & Km1 & Km1 \\
\hline Gardel & Gar & Gar & Gar & Gar & Gar & Gar & Gar & Gar \\
\hline
\end{tabular}

The pCS20 genomic region contains two overlapping genes. For further explanation of the mosaic see Section 3. NA, no amplicon.

The greatest number of distinct 16S and pCS20 genotypes is observed among the stocks of south and east African origin, but for both these genes all the west African sequences are identical to those of the southern African Kümm1 stock. These genes are widely used for characterisation of $E$. ruminantium field isolates.

The topologies of the unrooted phylogenetic trees inferred from individual gene sequences (trees not shown) were very varied, but with one consistent feature; each tree exhibited two major clades, one consisting of stocks of southern and eastern African 
origin (the S\&E clade), the other consisting of west African stocks plus the southern African Kümm1 stock (the W clade). Nine stocks fell reproducibly into one of the major clades, but 3 stocks were exceptions to this pattern; Kiswani from eastern Africa, Gardel from the Caribbean, and Kümm2 from southern Africa. Kiswani fell into the S\&E clade in all trees except the $\operatorname{sodB}$ tree, where it did not fall into either of the major clades. Gardel exhibited marked positional instability, sometimes falling in the S\&E clade, and sometimes in the $\mathrm{W}$ clade. Kümm2 was even more positionally unstable, not falling into either of the major clades in the 16S, pCS20, ftsZ and nuoB trees, while it fell in the $\mathrm{W}$ clade in the groEL tree and in the $\mathrm{S} \& \mathrm{E}$ clade in the $\operatorname{sodB}$ tree. In addition, Kümm2 showed unusually long branches in the pCS20, ftsZ and nuoB trees. Pairwise sequence identity calculations for all pairs of orthologs showed that Kümm2 was the most divergent of all the stocks for each gene (Table 4), and for the pCS20, ftsZ and nuoB genes this divergence was markedly greater than that of any of the other sequence pairs, which reflects the long branches seen in the corresponding trees. Because of this divergence, and because we could not obtain a gltA sequence from Kümm2, we omitted it from the concatenated phylogenetic analysis. In the concatenated tree of the remaining 11 stocks (Fig. 1) the consistent feature of the individual gene trees is very clearly exhibited; the stocks are separated into two major clades dependent upon their geographical origin, the S\&E clade and the W clade, which anomalously includes the southern African Kümm1 stock. Kiswani fell into the S\&E clade with low bootstrap support, and Gardel fell into the S\&E clade, but deeply branching and with low bootstrap support. 
Table 4.

Selected characteristics of 132 pairwise sequence identities for seven core function genes from 12 different $E$. ruminantium stocks

\begin{tabular}{|c|c|c|c|c|c|c|}
\hline \multirow{2}{*}{$\begin{array}{l}\text { Characteristics } \\
\text { of sequence } \\
\text { pairs }\end{array}$} & \multicolumn{6}{|c|}{ Gene or genetic region } \\
\hline & $16 S$ & $\begin{array}{l}\text { rnc and } \\
\text { ctaG }\end{array}$ & groEL & $f t s Z$ & sodB & nuoB \\
\hline & & pCS20 & & & & \\
\hline Length used (bp) & 1408 & 1218 & 1339 & 1272 & 605 & 519 \\
\hline $\begin{array}{l}\text { Pair with lowest } \\
\text { pairwise identity }\end{array}$ & $\mathrm{Km} 2: \mathrm{Kis}$ & $\mathrm{Km} 2: \mathrm{Km} 1$ & $\mathrm{Km} 2: \mathrm{Kis}$ & Km2:Sank & $\mathrm{Km} 2: \mathrm{Sen}$ & $\mathrm{Km} 2: \mathrm{Gar}$ \\
\hline $\begin{array}{l}\text { Value of lowest } \\
\text { pairwise identity }\end{array}$ & $99.43 \%$ & $83.95 \%$ & $98.18 \%$ & $84.30 \%$ & $99.00 \%$ & $88.57 \%$ \\
\hline $\begin{array}{l}\text { Mean of } 110 \\
\text { pairwise } \\
\text { identities } \\
\text { omitting Kümm2 }\end{array}$ & $99.80 \%$ & $98.52 \%$ & $99.14 \%$ & $98.61 \%$ & $99.64 \%$ & $99.35 \%$ \\
\hline
\end{tabular}

The pCS20 genomic region contains two overlapping genes. For further explanation see Section 3.

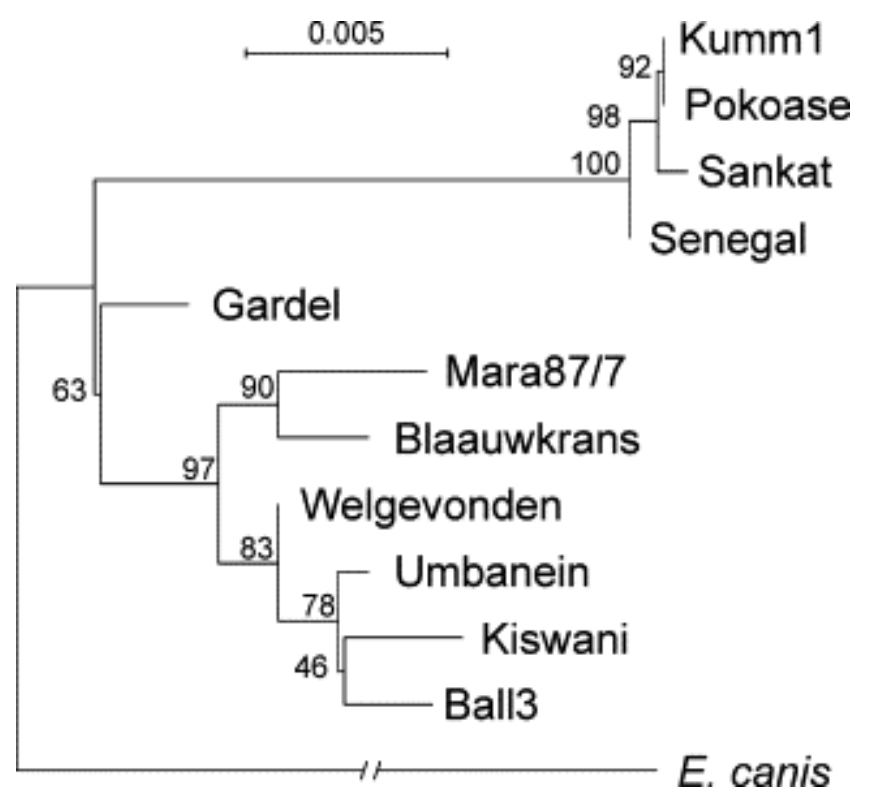


Fig. 1. Maximum likelihood tree, inferred using PHYML, of the concatenated sequences of eight core function genes of 11 stocks of E. ruminantium, using the concatenated sequences of their E. canis orthologs as the outgroup root. The scale bar indicates 1 nucleotide substitution per 200 bases.

\section{Discussion}

There were fewer individual sequences for each gene than there were stocks (Table 3), suggesting that inter-genome recombination has occurred between different stocks, and the mosaic of sequence identities shows that all stocks except Gardel appear to have undergone recombination. Gardel, the only Caribbean stock, had unique sequences for each of the eight genes. Of the southern and eastern African stocks, all except Kümm1 show evidence of recombination between themselves, but none with the western African stocks. The southern African Kümm1 stock is anomalous in that it shares no orthologs with any other southern or eastern African stock, but shows recombination with all the west African stocks. The only other evidence of recombination among the western African stocks is that Pokoase and Senegal share a ftsZ ortholog.

E. ruminantium has no plasmids, phages, insertion sequences, or genes for pilus assembly (Collins et al., 2005) which mediate recombination in many bacteria. However, with the exception of virB7, the genes required for the assembly of a channel for bacterial competence are present (Collins et al., 2005). This suggests that E. ruminantium may be naturally transformable (Thomas and Nielsen, 2005), actively capable of DNA uptake and homologous recombination by mechanisms which are currently not well understood. The most likely time for recombination to occur seems to be within the tick after ingestion of a blood meal from an animal carrying a mixture of $E$. ruminantium genotypes and before establishment of the organism in gut epithelial cells. This occurs about 15 days after the ticks have fed (Kocan and Bezuidenhout, 1987) and it is possible that DNA from degraded E. ruminantium chromosomes is taken up by surviving organisms during the extracellular period. Note that multiple E. ruminantium $16 \mathrm{~S}$ genotypes often occur in blood samples from animals in the field, although not in ticks removed from the same animals (Allsopp et al., 2006). This may be due to infection 
exclusion, which is known to occur with Anaplasma marginale in Dermacentor variabilis ticks (de la Fuente et al., 2003).

The individual gene trees exhibited variable topologies, as a result of the inter-genome recombination, and a consistent two-clade structure, which indicates a lack of recombination between stocks in the different clades. Kümm1 (southern Africa) consistently grouped with the western African stocks and showed ample evidence of recombination with them. Kümm2 had unique sequences for all genes except $\operatorname{sodB}$, and the pCS20, ftsZ and nuoB genes were unusually divergent from all their orthologs (Table 4). Since we could obtain no amplicon of the gltA gene that too is probably unusually divergent, and we therefore omitted Kümm2 from the concatenated phylogenetic tree (Fig. 1). This tree shows the clear separation of stocks into the S\&E clade and the $\mathrm{W}$ clade, the latter including Kümm1 from southern Africa. The branch lengths show the greater genetic variability of the genes in the S\&E clade as compared to the W clade, an effect also seen with the highly polymorphic map 1 gene (Allsopp et al., 2001), suggesting that E. ruminantium may have evolved in southern or eastern Africa and spread more recently to western Africa. Kümm1 is closely related to the western African Senegal stock, and many of the Kümm1/Senegal sequences are shared by all the stocks in the $\mathrm{W}$ clade, suggesting that the west African E. ruminantium genotypes may be derived from an ancestral strain similar to Senegal, the most deeply-branching member of the W clade, which spread to western Africa. If this is the case then Kümm1 has recently been reintroduced into southern Africa, perhaps together with Kümm2, since both stocks were obtained from a single field isolate (Zweygarth et al., 2002).

The clear separation between the $\mathrm{S} \& \mathrm{E}$ and $\mathrm{W}$ clades suggests that there may be some restriction to gene flow between the two areas. The most important vectors of heartwater in Africa are A. variegatum and A. hebraeum, of which the latter occurs only in southern Africa (Bezuidenhout, 1987). A distribution map of A. variegatum shows the highest population densities in two areas, one stretching up the eastern side of the continent, from Mozambique to the Red Sea, and the other occupying the north western part of the continent south of the Sahara ([Walker and Olwage, 1987] and [Walker et al., 2003]). A region of lower population density separates these two areas and this could well be the reason for the restricted gene flow between the stocks in the two clades. 
It has been estimated that the Gardel and Welgevonden stocks diverged from a common ancestor 2-4 million years ago (Mya), based on patterns of nucleotide substitution (Hughes and French, 2007), or 3.5 Mya, based on 16S gene differences (Ochman et al., 1999). It is not surprising, then, that the core genes of Gardel are unique, and since they have only been separated from their African orthologs for about 300 years (Maillard and Maillard, 1998) this argues that the original Gardel stock taken to Guadeloupe was different from western, eastern and southern genotypes. This fits with the phylogenetic analysis, which places Gardel near the root of the tree and in neither of the main clades (Fig. 1). In 1674 the Compagnie du Sénégal was given sole mandate to trade in slaves and livestock between the Caribbean and Africa, from Cape Verde to the Cape of Good Hope (Maillard and Maillard, 1998). It is therefore possible that the Gardel genotype did not come from West Africa, as has long been assumed, but from western central Africa (Angola, the Congo or Gabon). The situation could be clarified by studying isolates from that region, but unfortunately none are currently available. Two isolates other than Gardel have been made in the Lesser Antilles, on the islands of Marie Galante and Antigua (Camus and Barré, 1987), and it would be very interesting to carry out some phylogenetic studies on these stocks.

\section{Conclusion}

Our studies of core function genes show that extensive inter-genome recombination occurs among E. ruminantium genotypes. The genetic variability of the stocks in southern and eastern Africa is much greater than that among the western African isolates, which suggests that the organism originated in the southern or eastern region of the continent. It is possible that the common ancestor of the western African stocks became established in the region after passing a genetic bottleneck constituted by a central African area with a low density of vector ticks. One of the typically western genotypes, Kümm1, appears to have been recently reintroduced into the southern African region. The unique Gardel stock belongs to neither the $\mathrm{S} \& \mathrm{E}$ clade nor the $\mathrm{W}$ clade, and may be descended from an ancestral stock from west central Africa where gene exchange with southern, eastern, and western genotypes may also be restricted by tick population dynamics. The core genes examined were evenly distributed around the genome, suggesting that recombination 
events are genome-wide. There is a larger reservoir of genetic diversity among $E$. ruminantium and related organisms than can be seen in the few well-characterized heartwater-causing stocks, and those genes involved in antigenicity, infectivity, virulence, and pathogenicity of the organism will be likely to be as susceptible to recombination as the core genes. This has important implications for vaccine development.

\section{References}

Allsopp et al., 2001 M.T. Allsopp, C.M. Dorfling, J.C. Maillard, A. Bensaid, D.T. Haydon, H. van Heerden and B.A. Allsopp, Ehrlichia ruminantium major antigenic protein gene (map 1 ) variants are not geographically constrained and show no evidence of having evolved under positive selection pressure, J. Clin. Microbiol. 39 (2001), pp. $4200-4203$.

Allsopp et al., 1999 M.T. Allsopp, C.M. Hattingh, S.W. Vogel and B.A. Allsopp, Evaluation of 16S, map 1 and pCS20 probes for detection of Cowdria and Ehrlichia species, Epidemiol. Infect. 122 (1999), pp. 323-328.

Allsopp et al., 2006 M.T.E.P. Allsopp, M.F. Van Strijp, E. Faber, A.I. Josemans and B.A. Allsopp, Ehrlichia ruminantium variants which do not cause heartwater found in South Africa, Vet. Microbiol. 120 (2006), pp. 158-166.

Bell-Sakyi et al., 1997 L. Bell-Sakyi, E.B.M. Koney, O. Dogbey, J.A. Abbam and K.G. Aning, Isolation and in vitro cultivation in Ghana of Cowdria ruminantium, the causative agent of heartwater. In: E.B.M. Koney and K.G. Aning, Editors, Proceedings of the 22nd Annual Congress of the Ghana Veterinary Medical Association, The Information Support Unit, Ministry of Food and Agriculture, Accra, Ghana (1997), pp. 46-51.

Bezuidenhout, 1987 J.D. Bezuidenhout, Natural transmission of heartwater, Onderstepoort J. Vet. Res. 54 (1987), pp. 349-351.

Camus and Barré, 1987 E. Camus and N. Barré, Epidemiology of heartwater in Guadeloupe and in the Caribbean, Onderstepoort J. Vet. Res. 54 (1987), pp. 419-426. Collins et al., 2005 N.E. Collins, J. Liebenberg, E.P. de Villiers, K.A. Brayton, E. Louw, A. Pretorius, F.E. Faber, H. van Heerden, A. Josemans, M. van Kleef, H.C. Steyn, M.F. van Strijp, E. Zweygarth, F. Jongejan, J.C. Maillard, D. Berthier, M. Botha, F. Joubert, C.H. Corton, N.R. Thomson, M.T. Allsopp and B.A. Allsopp, The genome of the 
heartwater agent Ehrlichia ruminantium contains multiple tandem repeats of actively variable copy number, Proc. Natl. Acad. Sci. U.S.A. 102 (2005), pp. 838-843.

de la Fuente et al., 2003 J. de la Fuente, E.F. Blouin and K.M. Kocan, Infection exclusion of the rickettsial pathogen Anaplasma marginale in the tick vector Dermacentor variabilis, Clin. Diagn. Lab. Immunol. 10 (2003), pp. 182-184.

Du Plessis, 1985 J.L. Du Plessis, A method for determining the Cowdria ruminantium infection rate of Amblyomma hebraeum: effects in mice injected with tick homogenates, Onderstepoort J. Vet. Res. 52 (1985), pp. 55-61.

Du Plessis and Kumm, 1971 J.L. Du Plessis and N.A. Kumm, The passage of Cowdria ruminantium in mice, J. S. Afr. Vet. Med. Assoc. 42 (1971), pp. 217-221.

Du Plessis et al., 1989 J.L. Du Plessis, L. Van Gas, J.A. Olivier and J.D. Bezuidenhout, The heterogenicity of Cowdria ruminantium stocks: cross-immunity and serology in sheep and pathogenicity to mice, Onderstepoort J. Vet. Res. 56 (1989), pp. 195-201. Guindon and Gascuel, 2003 S. Guindon and O. Gascuel, A simple, fast, and accurate algorithm to estimate large phylogenies by maximum likelihood, Syst. Biol. 52 (2003), pp. 696-704.

Haig, 1952 D.A. Haig, Note on the use of the white mouse for the transport of strains of heartwater, J. S. Afr. Vet. Med. Assoc. 23 (1952), pp. 167-170.

Hughes and French, 2007 A.L. Hughes and J.O. French, Homologous recombination and the pattern of nucleotide substitution in Ehrlichia ruminantium, Gene 387 (2007), pp. 3137.

Ishikura et al., 2003 M. Ishikura, S. Ando, Y. Shinagawa, K. Matsuura, S. Hasegawa, T. Nakayama, H. Fujita and M. Watanabe, Phylogenetic analysis of spotted fever group rickettsiae based on gltA, 17-kDa, and rOmpA genes amplified by nested PCR from ticks in Japan, Microbiol. Immunol. 47 (2003), pp. 823-832.

Jongejan et al., 1984 F. Jongejan, S.P. Morzaria, O.A. Shariff and H.M. Abdalla, Isolation and transmission of Cowdria ruminantium (causal agent of heartwater disease) in Blue Nile Province, Sudan Vet. Res. Commun. 8 (1984), pp. 141-145. Jongejan et al., 1991 F. Jongejan, M.J. Thielemans, C. Briere and G. Uilenberg, Antigenic diversity of Cowdria ruminantium isolates determined by cross-immunity, Res. Vet. Sci. 51 (1991), pp. 24-28. 
Jongejan et al., 1988 F. Jongejan, G. Uilenberg, F.F. Franssen, A. Gueye and J. Nieuwenhuijs, Antigenic differences between stocks of Cowdria ruminantium, Res. Vet. Sci. 44 (1988), pp. 186-189.

Kocan and Bezuidenhout, 1987 K.M. Kocan and J.D. Bezuidenhout, Morphology and development of Cowdria ruminantium in Amblyomma ticks, Onderstepoort J. Vet. Res. 54 (1987), pp. 177-182.

Kocan et al., 1987 K.M. Kocan, S.P. Morzaria, W.P. Voigt, J. Kiarie and A.D. Irvin, Demonstration of colonies of Cowdria ruminantium in midgut epithelial cells of Amblyomma variegatum, Am. J. Vet. Res. 48 (1987), pp. 356-360.

Lan and Reeves, 2001 R. Lan and P.R. Reeves, When does a clone deserve a name? A perspective on bacterial species based on population genetics, Trends Microbiol. 9 (2001), pp. 419-424.

Lee et al., 2003 J.H. Lee, H.S. Park, W.J. Jang, S.E. Koh, J.M. Kim, S.K. Shim, M.Y. Park, Y.W. Kim, B.J. Kim, Y.H. Kook, K.H. Park and S.H. Lee, Differentiation of rickettsiae by groEL gene analysis, J. Clin. Microbiol. 41 (2003), pp. 2952-2960. Maillard and Maillard, 1998 J.C. Maillard and N. Maillard, Historique du peuplement bovin et de l'introduction de la tique Amblyomma variegatum dans les îles françaises des Antilles: Synthèse bibliographique, Ethnozootechnie 1 (1998), pp. 19-36.

Ochman et al., 1999 H. Ochman, S. Elwyn and N.A. Moran, Calibrating bacterial evolution, Proc. Natl. Acad. Sci. U.S.A. 96 (1999), pp. 12638-12643.

Provost and Bezuidenhout, 1987 A. Provost and J.D. Bezuidenhout, The historical background and global importance of heartwater, Onderstepoort J. Vet. Res. 54 (1987), pp. 165-169.

Thomas and Nielsen, 2005 C.M. Thomas and K.M. Nielsen, Mechanisms of, and barriers to, horizontal gene transfer between bacteria, Nat. Rev. Microbiol. 3 (2005), pp. 711-721. Thompson et al., 1994 J.D. Thompson, D.G. Higgins and T.J. Gibson, CLUSTAL W: improving the sensitivity of progressive multiple sequence alignment through sequence weighting, position-specific gap penalties and weight matrix choice, Nucleic Acids Res. 22 (1994), pp. 4673-4680.

Uilenberg et al., 1984 G. Uilenberg, N. Barré, E. Camus, M.J. Burridge and G.I. Garris, Heartwater in the Caribbean, Prev. Vet. Med. 2 (1984), pp. 255-267. 
Van der Merwe, 1987 L. Van der Merwe, The infection and treatment method of vaccination against heartwater, Onderstepoort J. Vet. Res. 54 (1987), pp. 489-491. Van Heerden et al., 2004 H. Van Heerden, H.C. Steyn, M.T. Allsopp, E. Zweygarth, A.I. Josemans and B.A. Allsopp, Characterization of the pCS20 region of different Ehrlichia ruminantium isolates, Vet. Microbiol. 101 (2004), pp. 279-291.

Waghela et al., 1991 S.D. Waghela, F.R. Rurangirwa, S.M. Mahan, C.E. Yunker, T.B. Crawford, A.F. Barbet, M.J. Burridge and T.C. McGuire, A cloned DNA probe identifies Cowdria ruminantium in Amblyomma variegatum ticks, J. Clin. Microbiol. 29 (1991), pp. 2571-2577.

Walker et al., 2003 A.R. Walker, A. Bouattour, J.-L. Camicas, A. Estrada-Peña, I.G. Horak, A.A. Latif, R.G. Pegram and P.M. Preston, Ticks of Domestic Animals in Africa: A Guide to Identification of Species. Bioscience Reports, 43 Comiston Drive, Edinburgh EH10 5QR, U.K. (2003) pp. 51-63.

Walker and Olwage, 1987 J.B. Walker and A. Olwage, The tick vectors of Cowdria ruminantium (Ixodoidea, Ixodidae, genus Amblyomma) and their distribution, Onderstepoort J. Vet. Res. 54 (1987), pp. 353-379.

Weisburg et al., 1991 W.G. Weisburg, S.M. Barns, D.A. Pelletier and D.J. Lane, 16S ribosomal DNA amplification for phylogenetic study, J. Bacteriol. 173 (1991), pp. $697-$ 703.

Zweygarth et al., 2002 E. Zweygarth, A.I. Josemans, M.F. Van Strijp, H. Van Heerden, M.T. Allsopp and B.A. Allsopp, The Kümm isolate of Ehrlichia ruminantium: in vitro isolation, propagation and characterization, Onderstepoort J Vet. Res. 69 (2002), pp. $147-$ 153.

Corresponding author. Tel.: +27 12529 8426; fax: +27 125298312 .

${ }^{1}$ Present address: P.O. Box 13041, Onderstepoort 0110, South Africa. 